June 2018

\title{
"An Experimental Test of the Under-Annuitization Puzzle with Smooth Ambiguity and Charitable Giving"
}

Hippolyte d'ALBIS, Giuseppe ATTANASI and Emmanuel THIBAULT 


\title{
An Experimental Test of the Under-Annuitization Puzzle with Smooth Ambiguity and Charitable Giving*
}

\author{
Hippolyte d'ALBIS, Paris School of Economics (CNRS) \\ Giuseppe ATTANASI, University of Lille (LEM) \\ Emmanuel THIBAULT, Toulouse School of Economics
}

June 30,2018

\begin{abstract}
In a life-cycle model with a bequest motive, we study the impact of smooth ambiguity aversion to uncertain survival probabilities on the optimal demand for annuities. We implement a theory-driven laboratory experiment. First, a subject's ambiguity attitude is elicited in a simple experimental setting able to make the smooth ambiguity model operational. Then, in a two-period annuity-bequest decision problem, the subject's bequest in the second period is presented as a donation to a previously chosen charity, contingent to the subject being active after the first period. In line with the theoretical predictions, we find that ambiguity-averse (resp., loving) subjects invest less (resp., more) in annuities than ambiguity-neutral ones. Furthermore, subjects' contingent donation to the chosen charity increases in their investment in annuities only for sufficiently high levels of warm-glow altruism.
\end{abstract}

JEL classification: C91, D81, G22.

Keywords: Self-insurance; annuity; uncertain survival probabilities; smooth ambiguity aversion; charity; experiment.

\footnotetext{
${ }^{*}$ We thank Kene Boun My for experimental software programming. We thank Agnès Festré, Antonio Filippin, Pierre Garrouste, Andrea Guido, Olivier l'Haridon, Anne Stenger and the seminar participants at 2014 Longevity Risk Workshop at CEAR (GSU) in Atlanta, 2014 LABSI Workshop in Siena, 2015 ASFEE Conference in Paris, 2016 BETA Day in Strasbourg, 2017 IMEBESS Conference in Barcelona, University of Rennes 1, University of Nice Sophia-Antipolis, University of Milan, and University of Verona for useful discussions. H. d'Albis and G. Attanasi gratefully acknowledge financial support by the ERC (grant DU 283953). E. Thibault thanks the Chair Fondation du Risque/SCOR "Marché du risque et création de valeurs" for the financial support.
} 


\section{Introduction}

This paper contributes to the understanding of the determinants of a specific form of self-insurance -investment in annuities - through a theory-driven laboratory experiment.

Annuities are financial securities that help to deal with lifetime uncertainty and the linked variation in savings. They are designed to be a reliable means of securing a steady cash flow for individuals during their retirement years and to alleviate fears of longevity risk, or outliving one's assets. More precisely, an annuity is a contract between an individual and an insurance company. The individual puts money in, essentially investing through the insurance company. In exchange, the insurance company gives him the opportunity to annuitize that money, i.e., to receive guaranteed income payments for the rest of his/her life. The annuity provides constant returns - largely above those of bonds - if the bearer is alive, and no return otherwise. Therefore, this financial product should be particularly attractive for retirees who find themselves increasingly exposed to longevity risk, i.e., to the risk of being unable to sustain their consumption should they live longer than average.

According to the life-cycle model of consumption with uncertain lifetime proposed by Yaari (1965), agents who do not care for bequests should invest all their wealth in annuities. Thus, full annuitization should be the optimal strategy followed by a rational individual without altruistic motives (concerns for his/her spouse and children). Davidoff et al. (2005) have revisited Yaari's (1965) results in a simpler discrete-time setting and under a somewhat more general asset structure. They show that positive annuitization still remains optimal under very general specifications and assumptions, including intergenerational altruism and market frictions.

However, these theoretical predictions do not meet the facts. The predicted investment of wealth at retirement in actuarially fair annuities of typical 65-year-old individuals is by far higher than the actual demand for annuities, thereby leading to the so-called underannuitization puzzle. In fact, despite the retirement income benefits that annuitization provides, it has been and remains a relatively unpopular option. At the beginning of this century, the private annuity markets in Australia, Canada, Chile, Israel, Singapore, Switzerland, the UK and the US, was under-developed, especially relative to the life insurance market (see James \& Song 2001). ${ }^{1}$ The situation has not much changed in the last years, with elderly population showing a low willingness to invest in annuities even in countries where this product is easily accessible. ${ }^{2}$

\footnotetext{
${ }^{1}$ Johnson et al. (2004) documented that in US defined-contribution savings plans, only $10 \%$ of participants who left their job after age 65 in 1992-2002 annuitized their assets. They estimated that in the same period, among people at least 65 years old in the US, private annuities comprised just $1 \%$ of total wealth. Inkmann et al. (2011) analyzed data from the English Longitudinal Study of Ageing, a biannual panel survey among those aged 50 and over living in private households in England in 2002. They showed that only $6 \%$ of the households in their sample received income from voluntary annuitization.

${ }^{2}$ Benartzi et al. (2011) analyzed more than 103,000 payout decisions from 112 different US definedbenefit pension plans during 2002-2008. About half of elder participants took their entire retirement benefit as a lump sum, even though the annuity was the default option and opting out required time-consuming paperwork (see also Previtero 2014). In the UK, until 2014 the rules forced people to buy an annuity when they retired. Since March 2015, about 4.2 million British savers over the age of 55 have more freedom to manage their retirement pots. Customer research conducted shortly after the announcement indicated that only one in three people aged 50 to 75 intended to buy a traditional annuity, and then only for a
} 
Several theoretical extensions have been provided so as to account for the underannuitization puzzle (see Brown et al., 2013, for a review). Although the literature to date has failed to identify a sufficiently general explanation for consumers' aversion to annuities, it has nonetheless highlighted three factors that should be incorporated in life-cycle models so as to mitigate the puzzle.

First, the bequest motive. Lockwood (2012) extends Davidoff et al. (2005) in order to also account for actuarially unfair annuities. He finds that a combination of realistic pricing loads and moderate bequest motives can render annuities unattractive in an optimizing model. His findings are consistent with Yogo (2016), who needs a bequest motive to generate low welfare gains from annuity market participation in a model with health investments.

Second, an investment frame. Brown et al. (2008) propose that instead of evaluating annuities within a consumption frame (focusing on the end result of what the bearer can spend over time), one should adopt an investment frame (focusing on the intermediate results of return and risk features when choosing assets). They provide survey evidence that in an investment frame, individuals find annuities quite unattractive, exhibiting high risk without high returns, and thus prefer non-annuitized products. Their results are in line with $\mathrm{Hu} \&$ Scott (2007), which show how loss aversion (and other behavioral distortions) can make annuities look undesirable: annuities are viewed as risky gambles where potential losses loom larger than potential gains should the bearer die earlier than expected.

Third, uncertain survival probabilities. d'Albis \& Thibault $(2012,2018)$ extends the Yaari's (1965) framework by assuming that the individual does not know his/her survival probability. They show that for an individual with maxmin expected utility à la Gilboa \& Schmeidler (1989) or with smooth ambiguity preferences à la Klibanoff et al. (2005, henceforth KMM) it is optimal not to annuitize but to purchase pure life insurance policies instead. Reichling \& Smetters (2015) reach a similar conclusion through a different extension of Yaari (1965): they allow a household's mortality risk to be stochastic due to health shocks. In this framework, lifetime annuity still helps to hedge longevity risk, but the annuity's remaining present value is correlated with medical costs. They predict that most households should not hold annuities, and many should hold negative amounts.

In this paper we consider together these three factors potentially explaining the underannuitization puzzle. We propose an experimental study of a two-period life-cycle model with consumption and bequest similar to Davidoff et al. (2005), and we assume, as in Yaari (1965), no market imperfections and some warm-glow altruism. At period 1, an individual decides how to share his income between bonds and actuarially-fair annuities in an investment frame. He/she derives utility from a bequest that might happen at the end of period 1 or period 2 and, upon survival, from consumption in period 2. As discussed above, a bequest motive is necessary to obtain some partial annuitization but it does not eliminate the advantage of annuities since they return more, in case of survival, than regular bonds. As an additional factor of under-annuitization, we assume ambiguity aversion toward uncertain survival probabilities, and we model this aversion with smooth ambiguity preferences à la KMM, as in d'Albis \& Thibault (2018).

portion of their assets. Koch et al. (2015) estimate that annuities' share of in-retirement products could decline from the current $75 \%$ to about $30 \%$ to $40 \%$. 
The assumption of Knightian uncertainty (i.e., ambiguity) on survival probabilities receives strong empirical support.

It is natural that demand for annuities increases with life expectancy (see, e.g., empirical results in Inkmann et al. 2011). However, despite all the available information displayed in Life Tables, survival probabilities are nevertheless ambiguous to individuals, due to at least three reasons: $(i)$ a rather strong individual heterogeneity in the age at death (see, e.g., the empirical analyses in Edwards \& Tuljapurkar 2005, Bell \& Miller 2005, and Benartzi et al. 2011); (ii) changes in the distribution of survival probabilities at each age in the last century due to opposite factors such as medical progress versus the emergence of new epidemic diseases (see, e.g., Cutler \& Meara 2004); (iii) unreliable data about last years of life, due to small number of observations and absence of a consensus among demographers about the mean survival rate (see, in particular, Oeppen \& Vaupel 2002).

The assumption of an aversion toward the ambiguity of survival probabilities is also supported by a great deal of evidence. This does not only concern health issues (see, e.g., Viscusi et al. 1991 about individuals' aversion to ambiguous information on the risk of lymphatic cancer). It is also detected in real case studies on environmental risks (see Riddel \& Shaw 2006 on the unwillingness to be exposed to the "unknown" risks associated with nuclear waste transportation). Furthermore, and more importantly for our study, aversion to ambiguous survival probabilities has been somehow detected in portfolio and life-cycle decisions: Post \& Hanewald (2013) have shown that individuals are aware of longevity risk and that this awareness affects their savings decisions.

With all this in mind, the contribution of our study to the current debate on the self-insurance role of investing in annuities is twofold. In a laboratory experiment, we elicit ambiguity aversion and we show that - if interpreted as aversion to ambiguous survival probabilities - it is a good candidate to explain the empirically observed underannuitization puzzle. Furthermore, we analyze the interplay between this specific form of self-insurance and voluntary bequests (upon survival), through a novel experimental design where the "next generation" is a real charity receiving the subject's voluntary bequests soon after the end of the experiment.

Subjects' degree of ambiguity aversion is elicited in phase A of the experiment through a simple mechanism able to make KMM's smooth ambiguity model operational. Recall that, as in d'Albis \& Thibault (2018), aversion to ambiguous survival probabilities is introduced into the Yaari's (2005) annuity-bequest framework through a non-expected utility model (KMM). Several experimental studies (e.g., Halevy 2007, Chakravarty \& Roy 2009, and Conte \& Hey 2013) find support for KMM in choice under uncertainty. Here we rely on a simplified version of a mechanism in Attanasi et al. (2014), designed ad hoc to experimentally identify KMM-coherent subjects. It consists in a combined elicitation of two features of a subject's ambiguity attitude, namely the value-ambiguity attitude and the choice-ambiguity attitude. This provides a robust test of the sign of the ambiguity attitude that a subject discloses in the experiment. Subjects showing at the same time value-ambiguity aversion (resp., proneness) and choice-ambiguity proneness (resp., aversion) in phase A are not considered in the analysis of behavior in phase B. This is because their behavior in phase A is incoherent with the predictions of KMM, our reference model in phase $\mathrm{B}$. 
In phase $\mathbf{B}$ of the experiment, we let subjects participate in the two-period annuitybequest decision problem discussed above (life-cycle framework). In the first period, the choice between annuities and bonds is proposed to subjects in an investment frame ("investing" means choosing annuities, "not investing" means choosing bonds). As discussed above, in line with Brown et al. (2008), with such framing annuities should be unattractive to an ambiguity-neutral subject with low warm-glow altruism. The novelty of our approach is in the way we measure warm-glow altruism and in the mechanism we use to implement subjects' bequests to a next generation in the lab.

Bequests are presented as donations to a charity. Indeed, at the end of phase A, each subject is asked to indicate - through Web search - a charity to which he/she would like to donate part of the earnings he/she would eventually get in phase B. A short charity-related questionnaire follows. Our auxiliary assumption is that answers to this questionnaire provide a measure of the subject's utility from the act of giving to the charity in phase B. Donations to the charities are implemented by the experimenter within 24 hours by the end of the experiment, with each subject getting private E-mail confirmation of his/her own donation.

This feature of the design has two main advantages. On the one side, it allows us to create a tie between the donor and the bequest's receiver, which it would not be the case if the latter were a randomly matched subject in the lab. On the other side, it avoids undesired effects of post-experiment bequest sharing and unreliable measures of warm-glow altruism if the receiver were a relative or a friend of the experimental participant.

After Andreoni's (1989) model of warm-glow altruism, several experimental studies have confirmed that warm glow is an important factor in monetary donations to a charity (for a review, see Brown et al. 2013). In particular, Crumpler \& Grossman (2008) show that agents give some of their own money to charity even when their donation does not alter the total amount donated to the charity. That is, individuals are giving for pure warm-glow reasons, not to expand the amount available to the charity.

Some experiments have been run about how donors' behavior extends to environments with uncertain income. This literature is relevant for our experiment, since in phase B of our design subjects choose the amount of the bequest in period 2 through the strategy method, i.e., before the uncertainty about "survival" and the income in period 2 is resolved. In this regard, Kellner et al. (2015) have proved that it is cheaper to commit to donate to a charity before the uncertainty is resolved, and so a larger donation is required to maintain a positive image. This result is in line with Converse et al. (2012), who find that the combination of wanting an outcome and lack of control under uncertainty increases donations to charity, and suggest that this is due to a belief that one's donations increase the likelihood of the desirable outcome. For all these reasons, we should expect elicited bequests in phase B of our experiment to be larger than theoretically predicted. However, this effect is compensated by the fact that in our annuity-charity decision problem, charities receive a (involuntary) bequest also in the case of "no survival" in period 2, namely the amount invested in bonds in period 1. Thus, the above-mentioned behavioral distortions on the voluntary bequest in the favorable state of the world should be mitigated by the possibility of an involuntary bequest in the unfavorable one.

Our experimental results confirm the theoretical prediction of a negative impact of ambiguity aversion and a positive impact of ambiguity proneness on the demand for an- 
nuities. Indeed, in period 1, ambiguity-averse subjects invest significantly less in annuities than ambiguity-neutral ones, and ambiguity-loving subjects invest significantly more than the latter. Furthermore, warm-glow altruism and giving play no significant effect on the demand for annuities.

In period 2, as assumed in our theoretical framework, we find that the way the subject shares his/her financial wealth if active is independent from his/her ambiguity attitude. In line with the theory, we observe that the amount the subject decides to keep for him/herself is increasing in the annuities purchased in period 1. However, the subjects' bequest to the chosen charity is non-decreasing in the investment in annuities. We find it increasing only for those subjects donating to charities which they perceive as "closer" in terms of own participation and/or involvement, thereby experiencing a sufficiently high level of warm-glow altruism through their voluntary donation.

The rest of the paper is structured as follows. Section 2 describes our experimental design. Section 3 presents our behavioral predictions. Section 4 presents and discusses our experimental results in light of the theoretical predictions. Section 5 concludes by framing our contribution within the experimental literature of self-insurance decisions.

\section{An experiment on annuities and charitable giving}

\subsection{The experimental protocol}

Participants (60 male, 40 female) were 100 (67 undergraduate, 33 graduate) students of University of Strasbourg, at the Laboratory of Experimental Economics of Strasbourg (LEES). Students (70 in Economics, 7 in other social sciences, 9 in human sciences, and 14 in natural sciences) were recruited through ORSEE (Greiner 2015). Four sessions of 25 subjects each were conducted at the LEES. Each person could only participate in one of these sessions. The experiment was programmed and implemented using the platform www.econplay.org of the LEES.

Average earnings were $€ 22.57$, including an average transfer of $€ 4.00$ to a charity chosen by each participant during the experiment, as it will be explained below. The average duration of a session was 70 minutes, including instructions and payment. ${ }^{3}$

\subsection{The experimental design}

The experimental design is made of two phases (A and B), always implemented in the same order. At the end of the experiment, subjects are paid for each phase. However, instructions of phase B are given and read aloud only prior to that phase.

Phase $\mathbf{A}$ is made of tasks 1-4, presented in reverse order in half of the sessions (50 subjects for each order). At the end of the experiment, only one of the four tasks is randomly selected and actually performed, so as to determine earnings of phase A. Instructions of a new task are given and read aloud only prior to that task.

Task 1 is a choice between a lottery with known probabilities and a battery of ten fixed amounts of money (see Figure 1). More precisely, each subject is given two options, Left

\footnotetext{
${ }^{3}$ The English translation of the instructions is provided as an electronic supplementary material of this paper that can be found at www.giuseppeattanasi.wixsite.com/index/working-papers
} 
and Right. Option Left is a lottery $L^{1}$ with two outcomes, $€ 0$ and $€ 20$, and $50 \%$ probability each-10-ball urn with 5 yellow balls and 5 blue balls-i.e., $L^{1}=(20,0.5 ; 0,0.5) .{ }^{4}$ Option Right gives instead a sure amount $€ X_{i}$, with $X_{i}$ being an odd number with $X_{1}=1$ and $X_{10}=19$, and $X_{i}<X_{i+1}$ for each $i=1, \ldots, 9$. Each subject is asked to indicate whether he/she prefers Left or Right for each of the ten $X_{i}$. In particular, monotonicity is exogenously imposed: each subject is asked to choose the lowest $X_{i}$ for which he/she prefers option Right to option Left. ${ }^{5}$ Call this choice $X^{1}$, where 1 indicates task 1.

Subject's earnings in task 1: If at the end of the experiment this task is randomly selected for payment of phase $\mathrm{A}$, the computer randomly draws one of the ten amounts $X_{i}$. If, for this randomly drawn amount $\tilde{X}_{i}^{1}$, the subject has indicated that he/she prefers option Left, i.e., $\tilde{X}_{i}^{1}<X^{1}$, then lottery $L^{1}$ is played: one of the ten balls is randomly drawn by the computer, and his/her earnings are $€ 20$ ( €0) if the ball is yellow (blue). If for $\tilde{X}_{i}^{1}$ the subjects has indicated instead that he/she prefers option Right, i.e., $\tilde{X}_{i}^{1} \geq X^{1}$, his/her earnings are $\tilde{X}_{i}^{1}$.

Left Option: The urn contains 5 yellow balls and 5 blue balls.

Remind: Your winning color is

Please, choose between the Left Option (uncertain outcome) and the Right Option (sure outcome of X€).

\begin{tabular}{|c|c|c|c|}
\hline Left Option: Play the lottery below & Left & Right & $\begin{array}{c}\text { Right Option: Receive with certainty } \\
\text { the amount } X=\end{array}$ \\
\hline \multirow{10}{*}{$\begin{array}{l}\text { Gain }=20 € \text { if } \\
\text { Gain }=0 € \text { if }\end{array}$} & • & 0 & $1 €$ \\
\hline & 0 & 0 & $3 €$ \\
\hline & 0 & 0 & $5 €$ \\
\hline & 0 & 0 & $7 €$ \\
\hline & 0 & 0 & $9 €$ \\
\hline & 0 & 0 & $11 €$ \\
\hline & 0 & 0 & $13 €$ \\
\hline & 0 & 0 & $15 €$ \\
\hline & 0 & 0 & $17 €$ \\
\hline & 0 & • & $19 €$ \\
\hline
\end{tabular}

Figure 1: Computer screen in task 1 (phase A)

Task 2 is the same as task 1, apart from the fact that here option Left is a lottery $L^{2}$ with the same two outcomes as $L^{1}$ but unknown probabilities, i.e., $L^{2}=(20, p ; 0,1-p)$ and $p$ unknown. More precisely, subjects are told that 10-ball urn used for task 2 has

\footnotetext{
${ }^{4}$ Before the experiment starts, each subject is asked to choose one of two colors: yellow or blue. The chosen color is the one that will be associated to the highest of the two outcomes for each lottery that the subject would play in the experiment with an urn with yellow and blue balls. From now on, the experimental design is explained under the assumption that the color chosen by the subject before the beginning of the experiment is yellow. This is without loss of generality: the same rules of the decision problem also hold if assuming that the chosen color is blue, and inverting "yellow" with "blue" in what follows.
}

${ }^{5}$ For a comparable study where monotonicity is imposed in a similar task, see Attanasi et al. (2018). 
an unknown composition of yellow and blue balls: $p$ can take one of the eleven values in $\{0,0.1, \ldots, 0.9,1\}$ with any probability. In terms of Figure 1, option Left indicates an urn with 10 grey balls, rather than 5 yellow balls and 5 blue balls.

Subject's earnings in task 2: Similarly to task 1, the comparison between $X^{2}$ - the lowest $X_{i}$ for which the subject prefers option Right to option Left in task 2 - and $\tilde{X}_{i}^{2}$ - the computer's randomly selected amount in task 2 - determines the subject's earnings. However, if $\tilde{X}_{i}^{2}<X^{2}$, and so lottery $L^{2}$ is played, the random draw of a ball by the computer is made from an urn with unknown composition.

Task 3 is a choice between ten two-outcome lotteries $L_{1}^{3}, L_{2}^{3}, \ldots, L_{10}^{3}$ with the same probabilities and different outcomes (see Figure 2). Since the same 10-ball urn with 5 yellow balls and 5 blue balls of task 1 is used, all lotteries in task 3 are of the type $L_{j}^{3}=\left(\bar{x}_{j}, 0.5 ; \underline{x}_{j}, 0.5\right)$, with $j=1,2, . ., 10$ being the line index in Figure $2, \bar{x}_{j}=10+j$ and $\underline{x}_{j}=10-j$. Hence, all lotteries in the battery have the same mean (€10), with standard deviation increasing with $j$, and $L_{10}^{3}$, the last lottery of the battery (the one with greatest standard deviation), being the same as $L^{1}$ in task 1 . Call $j_{3}^{*}$ the chosen line and $L_{j^{*}}^{3}$ the chosen lottery in task 3 .

Subject's earnings in task 3: If at the end of the experiment this task is randomly selected for payment of phase A, the computer randomly draws one of the ten balls of the urn with known composition ( 5 yellow balls, 5 blue balls). The subject's chosen line $j_{3}^{*}$ in task 3 determines the played lottery $L_{j^{*}}^{3}$ : if the randomly drawn ball is yellow, the subject's earnings are $\left(10+j_{3}^{*}\right)$ euros; otherwise, his/her earnings are $\left(10-j_{3}^{*}\right)$ euros.

\begin{tabular}{l} 
The urn contains 5 yellow balls and 5 blue balls. \\
Remind: Your winning color is \\
Please, choose one of the 10 lines below: \\
You play the lottery below \\
\hline
\end{tabular}

Figure 2. Computer screen of task 3 (phase A)

Task 4 is the same as task 3 (the ten lotteries $L_{j}^{4}$ with $j=1,2, \ldots 10$ have the same two outcomes as $L_{j}^{3}$ for each $j$ ). However, outcome probabilities are unknown, i.e., $L_{j}^{4}=$ $\left(\bar{x}_{j}, p ; \underline{x}_{j}, 1-p\right)$ and $p$ unknown, as in task 2: subjects are told that 10-ball urn used for 
task 4 has an unknown composition of yellow and blue balls: $p$ can take one of the eleven values in $\{0,0.1, \ldots, 0.9,1\}$ with any probability. In Figure 2, the urn is shown with 10 grey balls inside, rather than with 5 yellow balls and 5 blue balls.

Subject's earnings in task 4: Differently from task 3, the random draw of a ball by the computer is made from an urn with unknown composition. As in task 3, the subject's chosen line $j_{4}^{*}$ determines the played lottery $L_{j^{*}}^{4}$.

At the end of phase A, none of the four tasks is actually performed. Subjects move directly to phase B.

Phase $\mathbf{B}$ begins with each subject being asked to indicate a charity to which he/she would like to donate part of the earnings he/she would get in the decision problem he/she will participate in phase $\mathrm{B}^{6}{ }^{4} \mathrm{~A}$ short charity-related questionnaire follows. It is meant to elicit the relation of the subject with the chosen charity ${ }^{7}$ and his/her perceptions of others' and own altruism. ${ }^{8}$

Subjects face the choice of the charity and the related questionnaire before instructions of the decision problem they will participate in phase B are given. This is an investment-donation two-period decision problem. In period $\mathbf{1}$ each subject is given 10 euros and he/she has to decide how many of them to invest, where $a \in\{0,1, \ldots, 10\}$ is the invested amount and $10-a$ the amount not invested.

There are two possible outcomes in period 2 for the invested amount in period 1. These two outcomes are determined through a 10-ball urn with unknown composition of yellow and blue balls: subjects are told that this urn is of the same type of those used for tasks 2 and 4 of phase A. If a yellow ball is randomly drawn at the beginning of period 2 , then in period 2 the invested amount is multiplied by $2(2 a)$. If a blue ball is randomly drawn at the beginning of period 2 , then in period 2 the invested amount is lost (0).

The random draw of a ball from the urn at the beginning of period 2 also determines whether or not the subject is active in period 2 .

If the drawn ball is yellow, then the subject is active in period 2: his/her total wealth at the beginning of period 2 is given by the sum of the amount not invested and two times the invested amount, i.e., $(10-a)+2 a=10+a$ euros. Then, in period 2 the subject chooses how much of this $(10+a)$ euros he/she wants to donate to the previously chosen charity $(x)$ and how much he/she wants to keep for him/herself $(10+a-x)$. Hence, $x$ is the voluntary donation to the charity, i.e. conditional to the subject being active in period 2 .

If the drawn ball is blue, then the subject is not active in period 2 (there is no choice the subject can make): the only amount that is not lost, i.e., the one not invested in period $1,(10-a)$ euros, is directly donated to the previously chosen charity. This is

\footnotetext{
${ }^{6}$ Each subject is given 5 minutes to find the website of the chosen charity and copy-paste it on the screen of the experimental software.

${ }^{7}$ The four questionnaire items are: "Since how many years you know this charity?"; "How many times you have already donated to this charity?"; "Did you ever participate in the activities of this charity?"; "Does any of your relatives or friends is directly concerned by this charity?".

${ }^{8}$ The two questionnaire items are, respectively: "Would you say that most of the time people only care about themselves or they try to help others?"; "Would you say that most of the time you only care about yourself or you try to help others?". Possible answers to each question are on a scale from 0 (only care about oneself) to 10 (help others).
} 
the involuntary donation to the charity, i.e., conditional to the subject not being active in period 2.

To summarize, if a yellow ball is randomly drawn at the beginning of period 2, the subject's earnings in phase $\mathrm{B}$ are $(10+a-x)$ and the donation to the charity is $x$, with $x$ being chosen by the (active) subject; otherwise, the subject earns nothing in phase $\mathrm{B}$ and the donation to the charity is $(10-a)$, with this donation not being chosen by the (inactive) subject.

After the instructions of the investment-donation two-period decision problem have bean read aloud by the experimenter, each subject is asked to go through two sets of four control questions, aimed at stating his/her comprehension of the decision problem. Each set of questions involves an example of $(a, x)$ choice, and questions about the subject's earnings and the voluntary/involuntary donation to the charity for each color of the randomly-drawn ball.

Then, period 1 of the decision problem is performed: each subject chooses the invested amount $a$. At the end of period 1 , each subject chooses $x$, according to a meta-strategy method: he/she indicates the amount of the voluntary donation to the charity before knowing whether he/she will be actually active in period 2, i.e., before the random draw of the ball from the unknown urn. Phase B ends with the random draw of the ball from the unknown urn and the determination of subject's earnings from phase B and his/her donation to the charity.

Finally, one of the four tasks of phase A is randomly selected and performed, thereby determining subject's earnings from phase A.

The sum of earnings from phase A and from phase B is individually paid in cash to each subject at the end of the experiment. Subjects' donations to the charity are implemented by the experimenter immediately after the end of the experiment, and donation receipts sent to them within 24 hours after the end of the experiment. This last step of the design can be interpreted as period 3 of phase B, where experimental subjects are no more active, independently from their behavior and random events in periods 1 and $2 .{ }^{9}$

\subsection{Comments on the experimental design}

In this section we comment on some important features of the experimental design, and provide motivations for specific design choices.

Ambiguity characterizes the decision problems in tasks 2 and 4 of phase A and in period 1 of phase B. Phase A is meant to elicit a subject's value-ambiguity (tasks 1 and 2 ) and choice-ambiguity (tasks 3 and 4) attitudes within the smooth ambiguity model of Klibanoff et al. (2005), through a simpler and more direct version of the elicitation method in Attanasi et al. (2014). Several design features of phase A deserve to be discussed:

\footnotetext{
${ }^{9}$ More precisely, before participating in the decision problem of phase B, subjects are told that (quoting the Instructions) 'Immediately after having privately paid all participants' earnings, the experimenter will go through the charity's website indicated by each subject at the beginning of phase B, make the on-line donation and fill in the donation screen with the identity of the donor; the email confirmation of the electronic donation will be forwarded by the experimenter to the subject within 24 hours after the end of the experiment, so as to account for possible delays due to, e.g., any charities' website problems."
} 
- Order treatment. As in Halevy (2007), we also implement an order treatment. The goal is to check whether subjects' elicited ambiguity attitude is influenced by either presenting ambiguous tasks before unambiguous one - task 2 (4) before task 1 (3) - and/or presenting choice-ambiguity related tasks (3 and 4 ) before value-ambiguity related tasks (1 and 2). Notice that in Halevy (2007) only value-ambiguity attitude is elicited, while in Attanasi et al. (2014), where both attitudes are elicited, such order treatment is not implemented.

- Subject's choice of the "winning" color. An important issue raised in the experimental literature about Ellsberg-type tasks is subjects' thinking about strategic behavior and/or manipulations by the experimenter (see Schneeweiss 1973, Kadane 1992). To prevent the possibility that subjects might suspect they can be tricked on computer-generated realizations of random processes, at the beginning of the experiment we let each subject choose one of two colors (yellow or blue). The chosen color is associated to the highest of the two outcomes for each lottery that the subject would play in the experiment with a computerized urn with yellow and blue balls. This urn and the computer-generated realization are the same for all subjects conditional on the randomly selected task of phase A and on period 1 of phase B. The fact that the chosen "winning" color is not the same for all subjects prevents the possibility of strategic manipulations of the computergenerated realization by the experimenter.

- Instructions distributed prior to each task. Although subjects are told that phase A is made of four tasks, as in Halevy (2007) and Attanasi et al. (2014) instructions of a new task are given and read aloud only prior to that task. This minimizes across-task contamination in phase $\mathrm{A}$.

- Random draws performed at the end of the experiment. At the end of phase A, subjects know nothing about the composition of the unknown urns of tasks 2 and 4 . This prevents subjects from making any updating about the actual composition of the unknown urn of phase B. Moreover, such updating would be meaningless, since - although all characterized by the same level of ambiguity - the three urns used for task 2 of phase A, for task 4 of phase A, and for phase B are not the same urn. This design feature minimizes across-task and across-phase hedging behavior against ambiguity (see, e.g., Bade 2015).

Phase B is meant to elicit subjects' behavior in a life-cycle framework $\grave{a}$ la Davidoff et al. (2005), where the annuity vs. bond decision is taken in period 1, and voluntary bequests are chosen in period 2 and implemented in period 3 (after the end of the experiment). Several design issues of phase $\mathbf{B}$ deserve to be discussed:

- Simpler decision problem. In the experiment, the labels "annuity" and "bond" are never used in the instructions, so as to avoid framing effects. We use the more neutral wording "invested amount" and "amount not invested", respectively. This, coupled with a return on bonds set equal to 1 in the experiment, allows us to present the subjects with a simple investment problem where the invested amount $a$ is the demand for annuities and the amount not invested $(10-a)$ is the demand for bonds. The fact that the demand for bonds is a pure transfer of the initial endowment from period 1 to period 2 is without loss of generality, given that in the general version of the annuity-bond trade-off problem, the return on bonds is independent of whether the subject is "alive" (active) or not in period 2 (see d'Albis \& Thibault 2018). Furthermore, the experimental implementation of the three periods of phase B is in line with the return on bonds being set equal to 1 . In fact, the time 
lag between period 1 and period 2 is very short (period 2 starts immediately after the end of period 1). Same is for period 2 and period 3 (bequest implementation): the experimenter implements the subject's bequest immediately after the end of the experiment, and the bequest receipt is sent to the subject within 24 hours (same short time lag between bequest decision and bequest implementation for all subjects in the experiment).

- Bequests as charity donations. In a life-cycle framework à la Davidoff et al. (2005)see Section 3-, both voluntary and involuntary bequests are intended as money that the subject gives to the next generation. In particular, the subject's voluntary bequest $x$ is the money given if "alive" in period 2, and the involuntary bequest $(10-a)$ is the money left if not "alive" in period 2. Given our interest in understanding whether intergenerational altruism plays a role in annuitization, we tried to relate the bequest's receiver (outside the experiment) to the donor (in the experiment). We decided not to involve a subject's relative or friend as bequest receiver, mainly for two reasons: first, it would not have been possible to check ex-post the exact sharing of the subject's bequest between his/her relative or friend and him/herself; second, measuring the subject's altruism toward a relative or friend would have lead to similarly high levels of elicited altruism in the subject pool, with no heterogeneity in the distribution of this idiosyncratic feature. Rather, we let subjects in the experiment indicate - before knowing the decision problem in phase B - a charity as bequest recipient. The fact that the subject's bequest is implemented-immediately after the experiment - by the experimenter (who provides the subject with the charity donation receipt) guarantee ex-post check of bequest implementation. Finally, the charity-related questionnaire allows us to measure, among other things, the subject's links with the chosen charity and thereby his/her level of warm-glow altruism toward it.

- Meta-strategy method for voluntary bequest elicitation. In a life-cycle framework à la Davidoff et al. (2005), the voluntary bequest choice $x$ should be made in period 2, and only if the subject is "alive," i.e., active, in period 2. However, following a widely-used method in experimental economics, in the experiment each subject is asked to choose $x$ before period 2. This allows us to elicit $x$ also for those subjects who will not be active in period 2, due to an unfavorable random draw at the end of period $1 .^{10}$

- Control questions. The two sets of four control questions about the decision problem in phase B are aimed at identifying subjects for whom we are sure that they have not perfectly understood the rules and/or the structure of payoffs of the decision problem in phase B. We include in this group all subjects that have made at least 1 mistake in the first set and at least 1 mistake in the second set of 4 control questions. ${ }^{11}$ Although these subjects are allowed to participate in the investment-donation two-period decision problem, we do not consider them in the data analysis of phase B (Section 4.4).

Finally, our payment protocol deserves some comments:

- Random-lottery incentive mechanism and accumulated earnings. In phase A, only one of

\footnotetext{
${ }^{10}$ Notice that, in terms of Yaari's (1965) and Davidoff et al. $(2005),(10+a-x)$ is the subject's consumption if alive in period 2. However, the labels "bequest", "consumption" and "alive" are never used in the instructions, again to avoid framing effects. We use the more natural wording "amount donated to the charity" for $x$, "amount kept by the subject" for $(10+a-x)$, and "active" rather than "alive".

${ }^{11}$ If a subject has made no mistake in the first set of four control questions, he/she is allowed to skip the second set of questions.
} 
the four tasks is randomly selected at the end of the experiment to determine participants' earnings in that phase. Here we adopt a random-lottery incentive mechanism - extensively used in economic experiments (see the survey in Cox et al. 2015) - with the twofold goal of obtaining no wealth effect between different decision tasks of phase A, and proposing bigger stakes to experimental subjects. Furthermore, in order to let subjects focus separately on each phase of the experiment, we paid earnings of both phase A and phase B. This accumulated payoff is finally assigned according to two independent random draws. This payment protocol should have minimized potential distortions linked to the randomlottery incentive mechanism in phase $\mathrm{A}$, in line with recent findings in the experimental literature (Cox et al. 2015).

- Phase A proposed before but paid after phase B. We propose to subjects phase A always before phase $\mathrm{B}$, so as to avoid investment decision and - more importantly-bequest decision in phase B being distorted by weird expectations about what will happen in subsequent phase A. However, we pay phase A always after subjects go through phase B, so as to avoid wealth effects (e.g., heterogeneity of previously collected earnings) on behavior in phase B.

- Same expected earnings in both phases. We set payoffs in each of the four decision tasks in phase A such that the ex-ante (i.e., before making the decision) expected value of a subject's earnings in phase A is equal to the ex-ante expected value of his/her earnings in phase B. In fact, the subject's ambiguity attitude in phase A is elicited for the same interval of lottery outcomes of the decision problem he/she faces in phase B. More precisely, the ten lines of task 4 of phase A (see the three central columns of Figure 2) represent the ten possible pairs of outcomes $(10+a, 10-a)$ for each positive annuitization in period 1 of phase $\mathrm{B}(a \in\{1,2, \ldots, 10\})$. This allows us to test whether a different behavior in period 1 of phase $\mathrm{B}$ compared to task 4 of phase $\mathrm{A}$ is due to a positive bequest $x$ in the former, which reduces the two lottery outcomes to $(10+a-x, 0)$ for the subject and increases them to $(x, 10-a)$ for the charity he/she has previously indicated.

\section{Behavioral Predictions}

In this section, first we show how the four tasks of phase A can be used to detect the sign of a subject's ambiguity attitude within the KMM model. Then, we derive behavioral predictions for phase B in terms of the impact of a subject's ambiguity attitude on his/her optimal investment in annuities, and of the latter on his/her "warm-glow" optimal charity donation.

\subsection{Phase A: Ambiguity Attitude}

We discuss the link between the four tasks of phase A and our operational definition of ambiguity aversion, which relies on Attanasi et al. (2014).

In Section 2.2 we called $X^{t}$ the lowest sure amount for which a subject prefers option Right to option Left in task $t \in\{1,2\}$ (see Figure 1). This Left-to-Right switching amount determines an interval estimate for the certainty equivalent of lottery $L^{t}$ in task $t \in\{1,2\}$ : the greater $X^{t}$, the higher his/her estimated certainty equivalent. With this in mind, the following definition can be introduced. 


\section{Definition 1 (value-ambiguity attitude)}

A value-ambiguity-averse subject values an ambiguous lottery less than its unambiguous equivalent with the same mean probabilities. Then, this subject shows value-ambiguity aversion if $X^{2} \leq X^{1}$, value-ambiguity neutrality if $X^{2}=X^{1}$, and value-ambiguity proneness if $X^{2} \geq X^{1}$.

In Section 2.2 we also called $j_{t}$ the subject's chosen line in task $t \in\{3,4\}$ (see Figure 2). The chosen line determines the outcome spread of the lottery $L_{j^{*}}^{t}$ played in task $t \in\{3,4\}$ : the greater the index $j_{t}\left(j_{t}=1, \ldots, 10\right.$ for each $\left.t\right)$, the greater the outcome spread of $L_{j_{t}}^{t}$. With this in mind, the following definition can be introduced.

\section{Definition 2 (choice-ambiguity attitude)}

A choice-ambiguity-averse subject chooses a less-risky lottery when the probability distribution over lottery outcomes is ambiguous (unknown probabilities). Then, this subject shows choice-ambiguity aversion if $j_{4} \leq j_{3}$, choice-ambiguity neutrality if $j_{4}=j_{3}$, and choice-ambiguity proneness if $j_{4} \geq j_{3}$.

In the KMM framework, "smooth ambiguity aversion" is shown to be equivalent to the concavity of the von Neumann-Morgenstern index function $\phi$ accounting for the attitude toward mean-preserving spreads in the induced distribution of the expected utility of the one-stage lottery conditional to the -in our experiment, 11-possible compositions of the unknown lottery. Gollier (2014) has shown that it is not true in general that the concavity of the $\phi$ function (value-ambiguity aversion) implies the choice-ambiguityaversion of the subject. In other words, a value-ambiguity-averse subject could choose a lottery with greater outcome spread when probabilities are unknown (task 4) than when they are known (task 3). However, Gollier (2014) provides sufficient conditions on the structure of the two-stage uncertainty to re-establish the link between the concavity of $\phi$ and ambiguity aversion. One of these sufficient conditions is that the different secondstage distributions of the lottery outcomes can be ordered by the Monotone Likelihood Ratio stochastic order. Indeed, this sufficient condition is satisfied by the second-stage distributions of lottery outcomes in tasks 1-4 of phase A (and in the decision problem of period 1 of phase B). Hence, we conclude that, in the smooth ambiguity framework, the two operational definitions of value-ambiguity attitude and choice-ambiguity attitude are equivalent in our experiment, and are satisfied if $\phi$ is concave. This justifies the following definition.

\section{Definition 3 (coherent-ambiguity attitude)}

A subject is coherent-ambiguity-averse if $X^{2} \leq X^{1}$ and $j_{4} \leq j_{3}$, with at least one of the two relations holding strictly; coherent-ambiguity-neutral if $X^{2}=X^{1}$ and $j_{4}=j_{3}$; coherentambiguity-loving if $X^{2} \geq X^{1}$ and $j_{4} \geq j_{3}$, with at least one of the two inequalities holding strictly.

Therefore, our operational definition of coherent-ambiguity attitude in the smooth ambiguity framework is based on a double-check: we compare subject's decisions in task 1 vs. task 2 and in task 3 vs. task 4 . The first comparison tells us whether, given the two second-stage lottery-outcomes, he/she prefers to know first-order probability $p$ than 
facing a mean-preserving spread of second-order probabilities over the all possible discrete probabilities $\widetilde{p} \in\{0,0.1, \ldots, 0.9,1\}$. The second comparison tells us whether he/she prefers a less risky lottery where this mean-preserving spread takes place. An ambiguity-averse subject should show both these preferences. Therefore, in Section 4.4 (test of behavioral hypotheses) subjects showing at the same time value-ambiguity aversion (resp., proneness) and choice-ambiguity proneness (resp., aversion) in phase A are not considered in the analysis of behavior in phase B.

\subsection{Phase B: Annuitization and Bequest}

This section relies on the theoretical model of d'Albis \& Thibault (2018) to obtain behavioral predictions for phase B. This model introduces the rationale for ambiguity proposed by KMM into a static model of consumption and bequest under uncertain lifetime similar to Yaari (1965) and Davidoff et al. (2005).

The length of life of the Decision Maker (DM, hereafter) is at most two periods, with death being uncertain at the end of period 1 and certain at the end of period 2. At period 1 , the DM is endowed with an initial wealth $w$ that can be shared between annuities $a$ and bonds $w-a$.

In exchange for each unit of the initial wealth, bonds return $R>0$ units of consumption in period 2, whether the DM is alive or not at the end of period 1; if the DM is not alive, the investment in bonds directly goes to the next generation, thereby generating an involuntary bequest at the end of period 1 .

Conversely, annuities return $R_{a} \geq R$ in period 2 if the DM is alive and nothing if he/she is not alive. Negative annuitization is not allowed $(a \geq 0)$. If alive in period 2 , the DM may allocate his/her wealth between consumption $c$ and voluntary bequest $x$ to the next generation. Since death is certain at the end of period 2, the latter is a voluntary bequest.

In the experiment we set the exogenous parameters of the problem such that the initial wealth $w=10$ euros, the annuities return $R_{a}=2$, and the bonds return $R=1$. Thus, the DM's budget constraint in period 2 writes:

$$
c=R_{a} a+R(w-a)-x=2 a+1 \cdot(10-a)-x=10+a-x
$$

with $c \geq 0, x \geq 0,0 \leq a \leq 10$.

The DM derives utility from the involuntary bequest at the end of period 1 and, upon survival, from consumption in period 2. Following Davidoff et al. (2005), d'Albis \& Thibault (2018) assume that whatever the length of the DM's life, bequests are received in period 3, involving additional return. Therefore, the voluntary bequest is $x R$, if the DM is alive in period 2 ; the involuntary bequest is $(10-a) R^{2}$, if he/she is not alive in period 2 . The parametrization $R=1$ makes the actual value of voluntary and involuntary bequests, respectively $x$ and $(10-a)$, independent from the period (2 or 3$)$ they are received by the next generation.

The state-dependent DM's utility is $u(c, x)$ if alive in period 2 and $v(10-a)$ if he/she is not alive. DM's utility if not alive (function $v$ ) measures his/her warm-glow giving to the next generation. However, in line with the literature on the economic valuation of risks to health and life (see, e.g., Viscusi \& Aldy 2003), we assume that the DM's utility is larger 
if he/she is alive (consumption and voluntary bequest) than if he/she is not (involuntary bequest). A separable utility if alive, $u(c, x)=h(c)+m(x)$, as in Yaari (1965) and Davidoff et al. (2005), by construction satisfies all the above assumptions.

The DM's survival probabilities are uncertain in period 1. More precisely, the DM does not know his/her own probability distribution but only knows the set of possible distributions. We assume that there exist states of nature associated with given survival probabilities that may be interpreted as health types, to which the DM subjectively associates a probability to be in. Hence, following KMM, we can model the lottery with unknown (survival) probabilities through second-order priors over first-order probability distributions. Let us denote the random (discrete) survival probability by $\widetilde{p}$ whose support is denoted $\operatorname{Supp}(\widetilde{p})$, and the DM's evaluation of the survival expectancy by $E(\widetilde{p})=p$. Given that $p=1 / 2$ by construction in tasks 1 and 3 of phase A, and assuming that the principle of insufficient reason holds, the subject has symmetric beliefs on the composition of the unknown urn of period 1. Hence, $E(\widetilde{p})=1 / 2$ in our implementation, and, as in Yaari (1965), we have annuities available for purchase that are actuarially fair, i.e., $R_{a}=R / p=2$.

The DM's state-dependent expected utility, denoted $\mathcal{U}(a, x, \widetilde{p})$, is thus also a random variable that writes:

$$
\mathcal{U}(a, x, \widetilde{p})=\widetilde{p} \cdot[h(10+a-x)+m(x)]+(1-\widetilde{p}) \cdot v(10-a) .
$$

We also assume that the DM has smooth ambiguity preferences à la KMM: ambiguity attitude is introduced using function $\phi$, whose concavity/linearity/convexity has been elicited in phase A. The utility function of the DM is then given by an expectation of an expectation. The inner expectations evaluate the expected utilities corresponding to possible first-order probabilities while the outer expectation aggregates a transform of these expected utilities with respect to the second-order prior. The utility function writes:

$$
\phi^{-1}(E(\phi(\mathcal{U}(a, x, \widetilde{p})))) .
$$

A concave (resp., convex) $\phi$ implies ambiguity aversion (resp., ambiguity proneness), while a linear $\phi$ identifies an ambiguity-neutral DM (subjective expected-utility maximizer).

The DM faces the following problem, denoted $\left(\mathcal{P}_{\phi}\right)$ :

$$
\begin{array}{cl}
\max _{a, x} & \phi^{-1}(E(\phi(\mathcal{U}(a, x, \widetilde{p})))) \\
\text { s.t. } & \mathcal{U}(a, x, \widetilde{p})=\widetilde{p} \cdot[h(10+a-x)+m(x)]+(1-\widetilde{p}) \cdot v(10-a) .
\end{array}
$$

Then, the solution $\left(a^{\star}, x^{\star}\right)$ of $\left(\mathcal{P}_{\phi}\right)$ satisfies the FOCs:

$$
\begin{gathered}
E\left(\phi^{\prime}\left(\mathcal{U}\left(a^{\star}, x^{\star}, \widetilde{p}\right)\right) \cdot\left[\widetilde{p} \cdot h^{\prime}\left(10+a^{\star}-x^{\star}\right)-(1-\widetilde{p}) \cdot v^{\prime}\left(10-a^{\star}\right)\right]=0,\right. \\
-h^{\prime}\left(10+a^{\star}-x^{\star}\right)+m^{\prime}\left(x^{\star}\right)=0 .
\end{gathered}
$$

Equation (4) remarks that the survival probability affects the DM's optimal demand for annuities in period 1. This probability is not objectively known, i.e., it is "ambiguous". Ambiguity aversion determines the optimal exposure to uncertainty. A more ambiguityaverse DM chooses to be less exposed, which means that he/she aims at smoothing the expected utilities computed in each state of nature. 
To explain this effect, let us consider a simple example with two states of nature, 1 and 2 , for which the survival probabilities are respectively $p_{1}$ and $p_{2}$. Using equation (2), the optimal difference of expected utilities in both states is thus:

$$
\left(p_{1}-p_{2}\right)\left\{\left[h\left(10+a^{\star}-x^{\star}\right)+m\left(x^{\star}\right)\right]-v\left(10-a^{\star}\right)\right\},
$$

which is proportional to the optimal difference between the utility if the DM lives for two periods and the utility if he/she lives for one period only. As the utility depends on the bequest, the sign of the latter difference is not a priori given. However, following d'Albis \& Thibault (2018) it can be easily proven that the latter difference is always positive and that reducing the demand for annuities reduces the difference (6).

The intuition is that, upon survival, the utility increases with the share of annuities in the portfolio. As a consequence, to reduce the exposure to life uncertainty, an ambiguityaverse DM has to increase his/her demand for bonds - in our experiment, the amount not invested, $(1-a)$ - and reduce his/her demand for annuities - in our experiment, the invested amount $a$. Conversely, an ambiguity-loving DM would prefer to increase the exposure to life uncertainty, by increasing the difference (6). This would lead to reduce $(1-a)$ and increase $a$.

Based on this reasoning, we elaborate our first, and most important, behavioral hypothesis. It concerns period 1 of phase B of our experiment:

Hypothesis 1 [Ambiguity over Annuity in period 1]. The invested amount a in period 1 of phase B is significantly lower (resp., higher) for an ambiguity-averse (resp., ambiguity-loving) subject than for an ambiguity-neutral subject.

Hypothesis 1 essentially relies on equation (4), showing that the (unknown) survival probability affects the optimal demand for annuities in period 1. At the same time, equation (5) shows that, upon survival in period 2, the DM's optimal allocation of the financial wealth between consumption and bequest is not affected by this probability. Indeed, in the life-cycle decision problem of phase B, ambiguity attitude is only effective in period 1: having uncertainty been resolved between period 1 and period 2, the "survived" DM should not rely on his/her ambiguity attitude when choosing how to distribute his/her total wealth $(10-a)$ among voluntary bequest $x$ and his/her consumption $(10-a-x)$ in period 2 .

Based on this simple intuition, a second behavioral hypothesis, about period 2 of phase B of our experiment, can be elaborated:

Hypothesis 2 [Ambiguity over Wealth Allocation in period 2] Conditional on the ball of the winning color being randomly drawn at the end of period 1 , in period 2 the following occurs: the share of wealth if active used for the voluntary donation, i.e., $x /(10-a)$, and the complementary share kept by the subject as his/own private earning in phase $\mathrm{B}$, i.e., $(10-a-x) /(10-a)$, do not depend on the subject's ambiguity attitude.

Finally, equation (5) can be also used to define the application $x^{\star}=f\left(a^{\star}\right)$, which satisfies $0 \leq f^{\prime}(a) \leq 1$. Hence, at the optimum, if the DM survives, his/her consumption $10+a-f(a)$ and his/her bequest $f(a)$ increase with the demand for annuities. The latter increase depends on the DM's warm-glow altruism. Therefore, a third behavioral hypothesis can be introduced: 
Hypothesis 3 [Annuity over Consumption and Bequest in period 2] Conditional on the ball of the winning color being randomly drawn at the end of period 1 , in period 2 the following occurs: both the voluntary donation $x$ and the amount kept by the subject as his/own private earning in phase $\mathrm{B},(10-a-x)$, are significantly higher for higher invested amounts in period 1.

In Section 4.3 we will show how the subject's declared links to the chosen charity are crucial features for us to detect his/her actual warm-glow altruism from voluntary donation to this charity. In fact, while the first part of hypothesis 3 (positive relation between annuity returns and period 2 consumption) also holds for selfish subjects, the second part (positive relation between annuity returns and period 2 bequest) only holdssee eq. (5) - for a sufficiently high level of warm-glow altruism $m(\cdot)$ involved by the voluntary donation $x$. Indeed, warm-glow altruism should be strong enough to offset the subject's utility $h(10+a-x)$ from keeping the higher return generated in period 2 (if alive) by the investment in annuities he/she made in period 1 .

\section{Data analysis}

In this section, first we report the distribution of subjects according to the elicited sign of ambiguity attitude in phase A. Then, we report raw statistics on the chosen charity and on answers to the charity-related questionnaire before phase B. Finally, we test the three behavioral hypotheses about phase B, elaborated in the previous section.

\subsection{Elicited ambiguity attitudes in phase A}

Figure 3 reports the distribution of elicited ambiguity attitudes of the 100 subjects according to their behavior in phase A. The left panel reports value-ambiguity attitudes (see Section 3.1, Definition 1: task 2 vs. task 1), the central panel reports choice-ambiguity attitudes (Definition 2: task 4 vs. task 3), the right panel reports coherent-ambiguity attitudes (Definition 3: coherence of definitions 1 and 2).

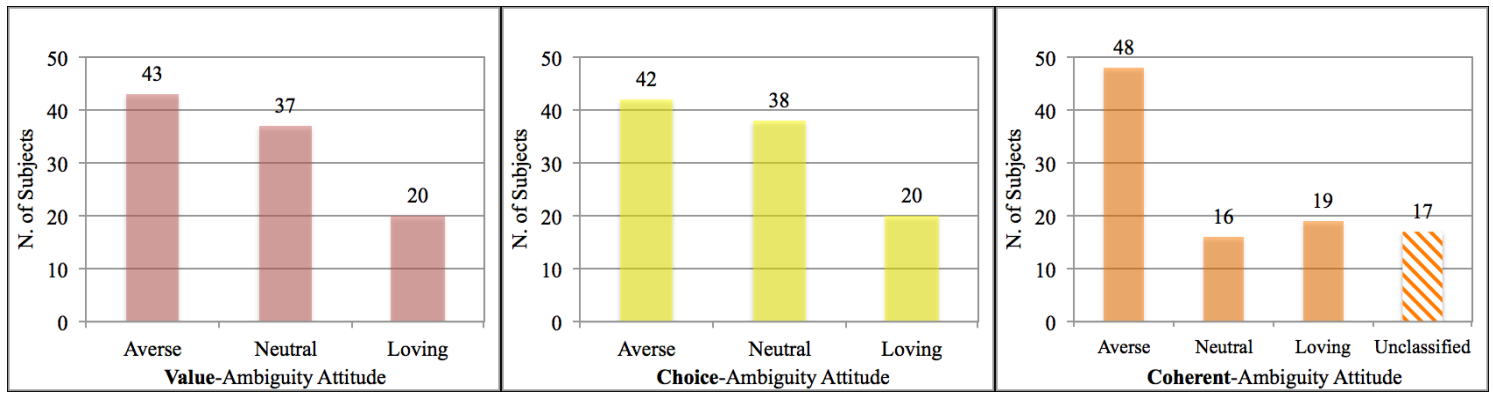

Figure 3. Distributions of value-ambiguity, choice-ambiguity, and coherent-ambiguity attitudes.

In line with the results of Attanasi et al. (2014), the majority of the subjects (around $4 / 10)$ are ambiguity-averse, and only few of them (2/10) are ambiguity-loving, independently of the dimension (value or choice). Furthermore, again in line with the previous 
study, we find that around half of the subjects show ambiguity aversion in at least one dimension (value or choice) and no ambiguity proneness in the other dimension. These subjects are coherent-ambiguity-averse. Consistently, around 2/10 subjects are coherentambiguity-loving (ambiguity-averse in at least one dimension and ambiguity non-averse in the other dimension). Only 16/100 subjects show neutrality to ambiguity in both dimensions. We find no significant treatment effect (reserve order of presentation of the four tasks) in the three distributions of Figure 3 ( $\chi^{2}$ test: $p$-value $=0.798$ for value-ambiguity attitude, 0.606 for choice-ambiguity attitude, 0.320 for coherent-ambiguity attitude).

We see the fact that our results are in line with those in Attanasi et al. (2014) as a first small methodological contribution of our paper, since our 4-task phase A is a much simpler version of their elicitation method of ambiguity attitude within KMM.

In the analysis of behavior in phase $\mathrm{B}$, we do not consider the 17 unclassified subjects in the right panel of Figure 3 (7/50 in the control treatment, 10/50 when tasks $1-4$ are presented in reverse order): these subjects show ambiguity aversion in one dimension and ambiguity proneness in the other one. Therefore, they did not pass our check of coherency of behavior within the smooth ambiguity framework of KMM. We call KMM-coherent the 83/100 subjects who passed the 4-task coherency test of phase A.

\subsection{Identification of "rational" subjects in phase B}

Figure 4 reports the distribution of subjects according to the number of incorrect answers in the two sets of 4 control questions administered at the beginning of phase B. Those questions concerned the rules and/or the structure of payoffs of the decision problem of phase $\mathrm{B}$. The $27 / 100$ subjects who made no mistake in the first set of four control questions were allowed to skip the second set of questions. Among the remaining 73 subjects, only 7 made at least one mistake in the second set of control questions. As anticipated in Section 2.3 , throughout this section we do not consider these 7 subjects, since for them we are not sure that they perfectly understood the decision problem of phase B.

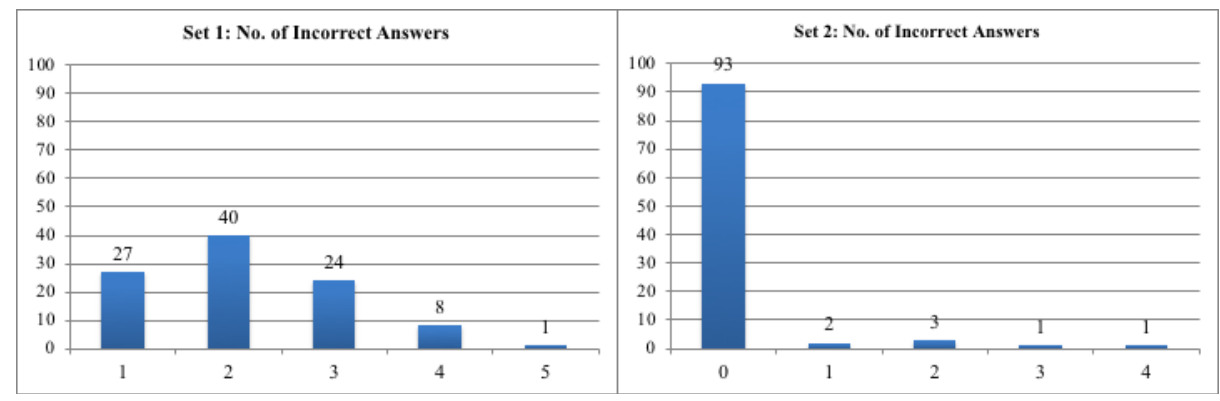

Figure 4. Distribution of incorrect answers in the two sets of control questions (about phase B).

Considering together this group of 7 subjects and the group of 17 unclassified subjects in Figure 3, we get 22 subjects who showed either bounded rationality at the beginning of phase $\mathrm{B}$ and/or a non-KMM rationalizable behavior in phase A (2 subjects belonged to both groups). Therefore, when testing our behavioral hypotheses in Section 4.4, we only consider the 78/100 subjects who showed full comprehension of the annuity-bequest 
problem of phase $\mathrm{B}$ and a behavior in phase A coherent with ambiguity attitude within KMM (i.e., our reference model of subjects' ambiguity attitude in phase B). From now on, we call these subjects rational-KMM-coherent.

\subsection{Charities and measures of warm-glow altruism}

Figure 5 reports the distribution of chosen charities at the beginning of phase B. 55/100 subjects chose a well-known international charity (red color) and 40/100 a national charity (yellow color). ${ }^{12}$ Only 5/100 chose a local charity (light yellow color), i.e., operating in a specific region of France. ${ }^{13}$

We see this as a second methodological contribution of our study: the combined implementation of these three features - $(i)$ charity chosen by the subject through a 5 -minute web search; (ii) charity donation implemented by the experimenter through the charity's Website immediately after the experiment; (iii) E-mail confirmation of the donation individually sent by the experimenter to the subject within 24 hours by the end of the experiment - induced the subjects to choose well-known and reliable charities, offering an efficient and transparent Website donation system. This also reduced the heterogeneity of subjects' choices in terms of "next generation" as recipient of their donations in phase B.

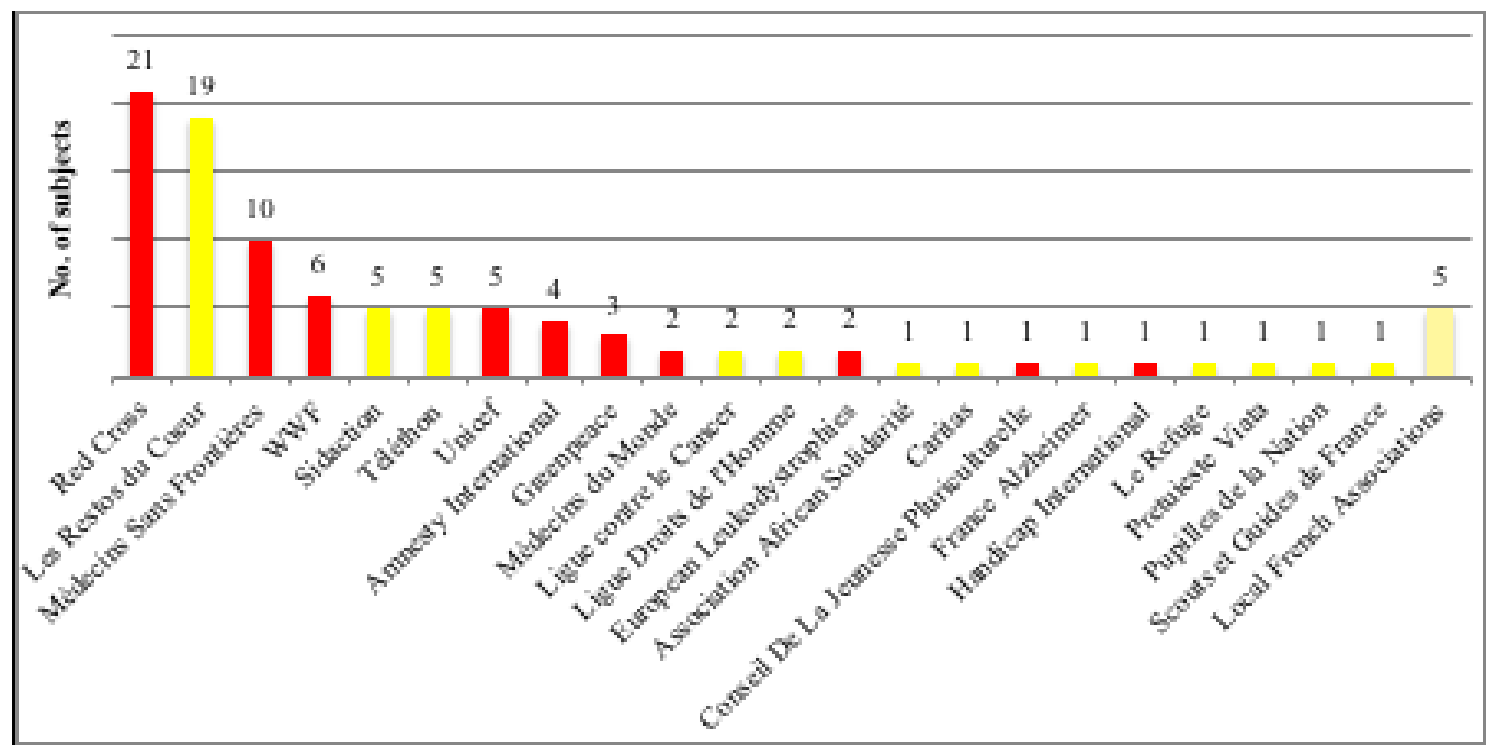

Figure 5. Distribution of subjects' chosen charities before the beginning of phase B.

Table 1 reports the distribution of answers to a short questionnaire administered after the choice of the charity. This questionnaire contained four items specific to the previously chosen charity, two items on the general perception of others' and own altruism, and items

\footnotetext{
${ }^{12}$ Of these, 47 are French charities, one is in Burkina Faso (Association African Solidarité), one is in Italy (Caritas), and another one in Romania (Pretuieste Viata).

${ }^{13}$ The five local (French) charities are: Association Les Disciples (Strasbourg), Virade de l'Espoir (Morbihan), Association de l'Espérance des Nécessiteux en l'Amélioration du Futur (Strasbourg), De l'Eau pour l'Afrique (Grenoble), La Main du Coeur - Aide aux Enfants (Strasbourg).
} 
related to subjects' idiosyncratic features. Average values of these variables are shown in Table 1 across the two types of chosen charities of Figure 5: international (55, red color), and national or local (45, yellow color). The last column reports the results of a Mann-Whitney equality-of-populations rank test (adjusted for ties). In square brackets, we report the same statistics and results of tests concerning the subgroup of 78 rational-KMMcoherent subjects on whom the analysis in Section 4.4 will rely. We add this information in order to show that, besides having selected the same proportion of international, national and local chosen charities - resp., $55.1 \%$ (43/78), 39.7\% (31/78), and 5.1\% (4/78) -, our target group presents a distribution of answers to the questionnaire similar to the one of the whole sample of 100 subjects. Therefore, we claim that our theory-driven selection of the target group of subjects did not distort the charity-related measurement of warmglow altruism, and did not generate any bias in the distribution of elicited idiosyncratic features.

The four variables measuring subject's warm glow specific to the chosen charity indicates, respectively: the number of years the subject knew the chosen charity (Charity Know Years); how many times he/she previously donated to this charity (Charity No. Previous Donations); whether he/she ever participated in this charity's activities (Charity Participation dummy); whether any of his/her relatives or friends was directly concerned by this charity (Charity Relatives-Friends dummy). The two variables measuring the subject's general perception of others' and own altruism take values from 0 to 10 , according to their agreement with the statement that most of the time people try (resp., he/she tries) to help others rather than caring about themselves (resp., him/herself). Reported idiosyncratic features are gender ( 0 for male, 1 for female), age (categories 1-4: 18-19, 20-25, 26-30, 30-35 years old), graduate student dummy, economics student dummy.

\begin{tabular}{|c|c|c|c|}
\hline \multirow{2}{*}{$\begin{array}{l}\text { Charity-specific, altruistic } \\
\text { and idiosyncratic variables }\end{array}$} & \multicolumn{2}{|c|}{ Chosen Charity } & \multirow{2}{*}{$\frac{\text { Mann-Whitney test }}{p \text {-value }}$} \\
\hline & International & National/Local & \\
\hline Charity Know Years & $3.27[3.21]$ & $3.10[3.00]$ & $0.510[0.448]$ \\
\hline Charity No. Previous Donations & $0.69[0.60]$ & $0.89[0.97]$ & $0.438 \quad[0.362]$ \\
\hline Charity Participation & $0.18[0.16]$ & $0.33[0.34]$ & $0.083[0.067]$ \\
\hline Charity Relatives-Friends & $0.16 \quad[0.12]$ & $0.31 \quad[0.29]$ & $0.083 \quad[0.061]$ \\
\hline Altruism Others & $4.44[4.28]$ & $4.51[4.49]$ & $0.944 \quad[0.760]$ \\
\hline Altruism Own & $5.91[5.68]$ & $6.16 \quad[6.06]$ & $0.348 \quad[0.313]$ \\
\hline Female & $0.42[0.42]$ & $0.40[0.37]$ & $0.683 \quad[0.674]$ \\
\hline Age & $1.72[1.77]$ & $1.90[1.94]$ & $0.170[0.192]$ \\
\hline Graduate & $0.22[0.21]$ & $0.25 \quad[0.29]$ & $0.405[0.437]$ \\
\hline Economics & $0.51[0.53]$ & $0.60[0.69]$ & $0.259 \quad[0.179]$ \\
\hline
\end{tabular}

Table 1. Average charity-specific, altruistic, and personal features, disentangled by chosen charity. Note: For each average and test, the first value refers to the whole sample of 100 subjects. The second value, in square brackets, refers to the sub-sample of 78 rational-KMM-coherent subjects.

Table 1 shows that the fraction of subjects who participated in the activities of the chosen charity is significantly higher among those who chose a national or local rather 
than an international charity. Furthermore, around $1 / 3$ subjects choosing national or local charities had relatives or friends directly concerned by these charities; this fraction is significantly lower (less than $1 / 2$ ) across subjects choosing international charities. Both these differences seem reasonable. In fact, in real-life bequest decisions, international charities are more often chosen for reputation or loyalty reasons (in Table 1, the number of years a subject knew the chosen charity is higher, although not significantly, for international charities). National or local charities are instead chosen more often because of personal involvement and/or because a friend or relative is involved in or concerned by their activity. Table 1 also shows a higher (although, again, non-significantly) average number of previous donation to national or local charities than to international ones. In the last part of Section 4.4, we will use the fact that a subject has chosen a national or local rather than an international charity as a feature of higher warm-glow altruism toward that charity for the same voluntary donation selected in period 2 of phase B.

Finally, Table 1 shows no significant difference across the two categories of charities for all variables measuring subjects' general perception of altruism or idiosyncratic features. We interpret this result as further confirmation of the adequacy of our charity selection procedure, and elicitation of warm-glow motivations for charitable donations - interpreted as bequest to a next generation - in phase B.

\subsection{Test of behavioral hypotheses}

In this section, relying on the categorization of Sections 4.1-4.3, we test the three behavioral hypotheses elaborated in Section 3.2 about subjects' behavior in the annuity-bequest decision problem of phase $\mathrm{B}$.

Figure 6 reports in the left panel the distribution of subjects' demand for annuities (invested amount in period 1) of rational-KMM-coherent subjects. All subjects demanded a positive amount of annuities, with $27 \%$ of them (21/78) investing half of their endowment and $19 \%$ of them $(15 / 78)$ investing all their endowment (average investment $=57.4 \%$ ).
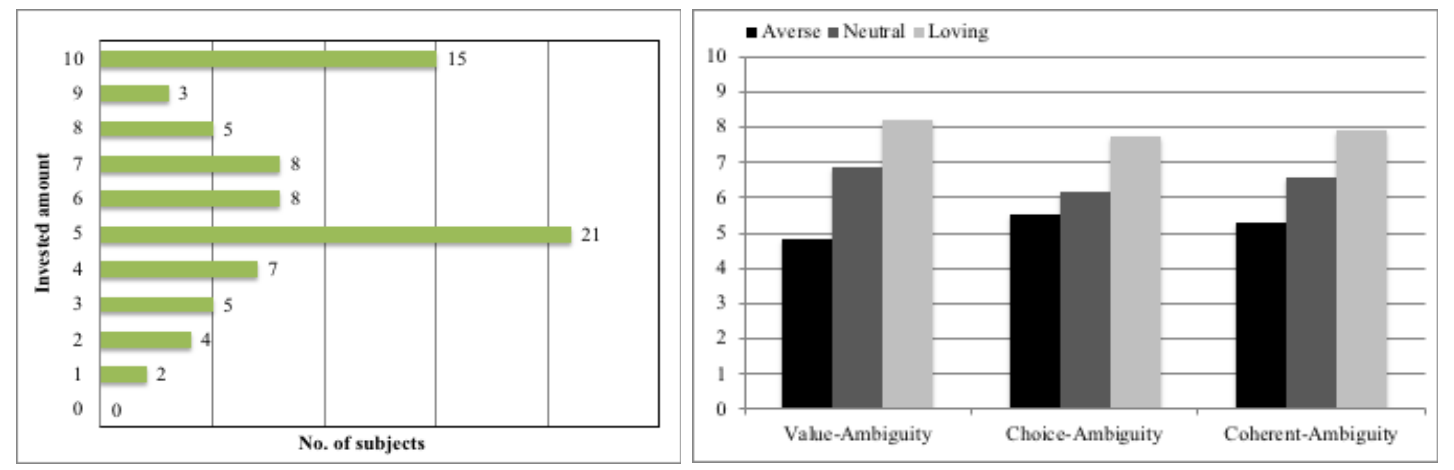

Figure 6. Frequency of invested amounts (left panel), and average invested amount by ambiguity attitude (right panel).

In the right panel, Figure 6 reports the average demand for annuities disentangled by the sign of the ambiguity attitude (aversion, neutrality, proneness) for rational-KMMcoherent subjects. A significantly different demand for annuities is found for the three 
categories of ambiguity attitudes, independent of whether we consider value-ambiguity, choice-ambiguity, or coherent-ambiguity attitudes (Kruskal-Wallis test, $p$-value $=0.000$, 0.060 , and 0.001 , respectively). Pairwise comparisons confirm a significantly lower demand for annuities by value-ambiguity-averse than by value-ambiguity-neutral subjects (MannWhitney test, $p$-value $=0.002$ ). They also confirm a significantly higher demand for annuities by choice-ambiguity-loving than by choice-ambiguity-neutral subjects (MannWhitney test, $p$-value $=0.093)$. Finally, a significantly lower demand for annuities is found among ambiguity-averse than among ambiguity-loving subjects, independently from the dimension of ambiguity attitude (Mann-Whitney test, $p$-value $=0.000$ for value-ambiguity, 0.018 for choice-ambiguity, and 0.000 for coherent-ambiguity).

To provide econometric support to the results shown in Figure 6, we run three regressions with the invested amount $a$ in period 1 of phase B as dependent variable. Since $a \in\{0,1, \ldots, 9,10\}$, we rely on Tobit models, left censored at 0 , and right censored at 10. ${ }^{14}$ In each of the three models, the main regressor is a dummy for subject's coherentambiguity aversion. Model I considers as regressors also the charity-related items (Charity Relatives-Friends dummy not included since correlated to Charity Participation dummy) and the subject's general perception of own altruism (general perception of others' altruism not included since correlated with the former). Model II includes instead controls for individual characteristics (Graduate dummy not included since it correlates with age), and for treatment effects (due to the different order of presentation of the four tasks of phase A). Model III considers together all the above mentioned regressors. Results of these three regressions are shown in Table 2.

\begin{tabular}{|c|c|c|c|c|c|c|}
\hline Dep. var.: Invested amount & \multicolumn{2}{|c|}{ Model I } & \multicolumn{2}{|c|}{ Model II } & \multicolumn{2}{|c|}{ Model III } \\
\hline Coherent-Ambiguity Aversion & \multicolumn{2}{|c|}{-2.45*** (0.67) } & \multicolumn{2}{|c|}{$-2.27 * * *(0.67)$} & \multicolumn{2}{|c|}{$-2.30 * * *(0.68$} \\
\hline Charity Know Years & -0.13 & $(0.23)$ & \multicolumn{2}{|c|}{-} & -0.12 & $(0.25)$ \\
\hline Charity No. Previous Donations & 0.04 & $(0.27)$ & \multicolumn{2}{|c|}{-} & -0.05 & $(0.27)$ \\
\hline Charity Participation & -0.05 & $(0.79)$ & \multicolumn{2}{|c|}{-} & -0.29 & $(0.84)$ \\
\hline Altruism Own & 0.11 & $(0.17)$ & \multicolumn{2}{|c|}{-} & 0.04 & $(0.17)$ \\
\hline Female & \multicolumn{2}{|c|}{-} & 0.31 & $(0.66)$ & 0.23 & $(0.73)$ \\
\hline Age & \multicolumn{2}{|c|}{-} & 0.73 & $(0.51)$ & 0.79 & $(0.56)$ \\
\hline Economics & \multicolumn{2}{|c|}{-} & -0.06 & $(0.67)$ & -0.16 & $(0.72)$ \\
\hline Treatment & \multicolumn{2}{|c|}{-} & -0.46 & $(0.67)$ & -0.40 & $(0.69)$ \\
\hline Constant & \multicolumn{2}{|c|}{$7.60^{* * *}(1.26)$} & \multicolumn{2}{|c|}{$6.97^{* * *}(1.75)$} & \multicolumn{2}{|c|}{$7.13^{* * *}(2.19)$} \\
\hline Log likelihood & \multicolumn{2}{|c|}{-170.30} & \multicolumn{2}{|c|}{-169.01} & \multicolumn{2}{|c|}{-168.73} \\
\hline No. of observations & \multicolumn{2}{|c|}{78} & \multicolumn{2}{|c|}{78} & \multicolumn{2}{|c|}{78} \\
\hline
\end{tabular}

Table 2. Tobit regressions explaining the invested amount of rational-KMM-coherent subjects in period 1 of phase B.

Note: Standard errors in parentheses, ${ }^{*} p<0.1,{ }^{* *} p<0.05,{ }^{* * *} p<0.01$.

\footnotetext{
${ }^{14}$ As Figure 6 shows, none of the rational-KMM-coherent subjects chose $a=0$ and only $15 / 78$ chose $a=10$. Therefore, we also run OLS regressions with the same three specifications of Table 2 , and found similar results. As further robusteness check, we also run Tobit regressions with clustered errors at the session level (25 subjects per experimental session). Also in this case, results are similar to those presented in Table 2. Results of all these regressions are available upon request.
} 
Table 2 shows that the only regressor explaining a subject's demand for annuities in period 1 is his/her attitude toward the ambiguous probability of being active ("alive") in period 2. In particular, ambiguity aversion elicited in phase A of the experiment significantly reduces the demand for annuities in phase B. Furthermore, the coefficient of the coherent-ambiguity aversion dummy is always significant at the $1 \%$ level in each of the three model specifications, thus providing robustness to this result: ambiguity aversion reduces the demand for annuities with or without controlling for the subject's warm-glow motivations and idiosyncratic features. A similar result is obtained if considering as regressor, rather than a dummy for ambiguity aversion, an ordered variable for subject's ambiguity attitude ( -1 for aversion, 0 for neutrality, +1 for proneness).

Notice that, although the coefficients of all charity-related measures of warm glow have the predicted (negative) sign in Model III, none of them is significant in either Model I or Model III. More precisely, we have tried several other specifications with charityrelated and perceived altruism variables as unique regressors (with or without controls for individual characteristics) and found that in none of them any of their coefficients is significant.

All this leads us to conclude that hypothesis $\mathbf{1}$ is verified.

The test of hypothesis 2 relies on the data reported in Figure 7 . The figure shows the subject's wealth allocation in period 2 if active ("alive"), i.e., if a ball of the winning color is randomly selected from the urn with unknown composition of balls (representing the subject's unknown "survival" probability). In particular, we highlight the share of this wealth the subjects would voluntary give $(x)$ to the chosen charity, disentangled by the sign of subjects' ambiguity attitude. Recalling that the total wealth if alive in period 2 is given by $(10+a)$, Figure 7 reports the average value of $x /(10+a)$ across rationalKMM-coherent subjects with the same ambiguity attitude. The complementary share, $(10+a-x) /(10+a)$, represents the portion of total wealth if active that the subject would keep for him/herself at the end of the experiment.

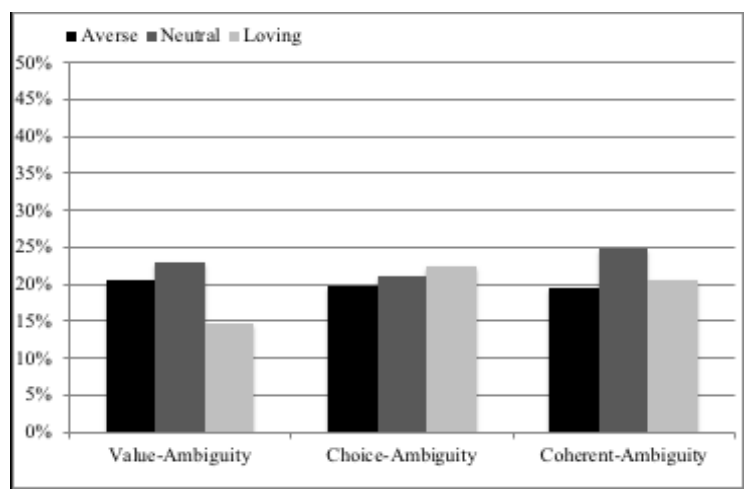

Figure 7. Voluntary donation as share of wealth if active in period 2, by ambiguity attitude.

For each dimension of ambiguity attitude (value, choice, or coherent) and each sign (aversion, neutrality and proneness) given the dimension, the average share of total wealth voluntary donated to the chosen charity is between $15 \%$ and $25 \%$. Therefore, no significant difference is found across different ambiguity attitudes if considering value-ambiguity 
(Kruskal-Wallis test, $p$-value $=0.251)$, choice-ambiguity $(p$-value $=0.492)$ or coherentambiguity $(p$-value $=0.308)$. Pairwise comparisons of ambiguity attitudes through the Mann-Whitney test confirms this result (lowest $p$-value $=0.113$, found for value-ambiguity neutral vs. loving, last two histograms of the first triplet of Figure 7).

Therefore, we can state that hypothesis $\mathbf{2}$ is also verified: The subjects' allocation of wealth between own consumption (experimental earnings in phase B) and voluntary bequest to the chosen charity is independent from the subject's ambiguity attitude.

We conclude this section with the test of hypothesis 3 . Figure 8 reports, in the left panel, subjects' private earnings (consumption) and voluntary donation (charity bequest) if active in period 2, for each invested amount (demand for annuities) in period 1. This panel refers to all rational-KMM-coherent subjects. The right panel reports the same statistics for the subgroup of such subjects who indicated a national or local charity at the beginning of phase $\mathrm{B}$.
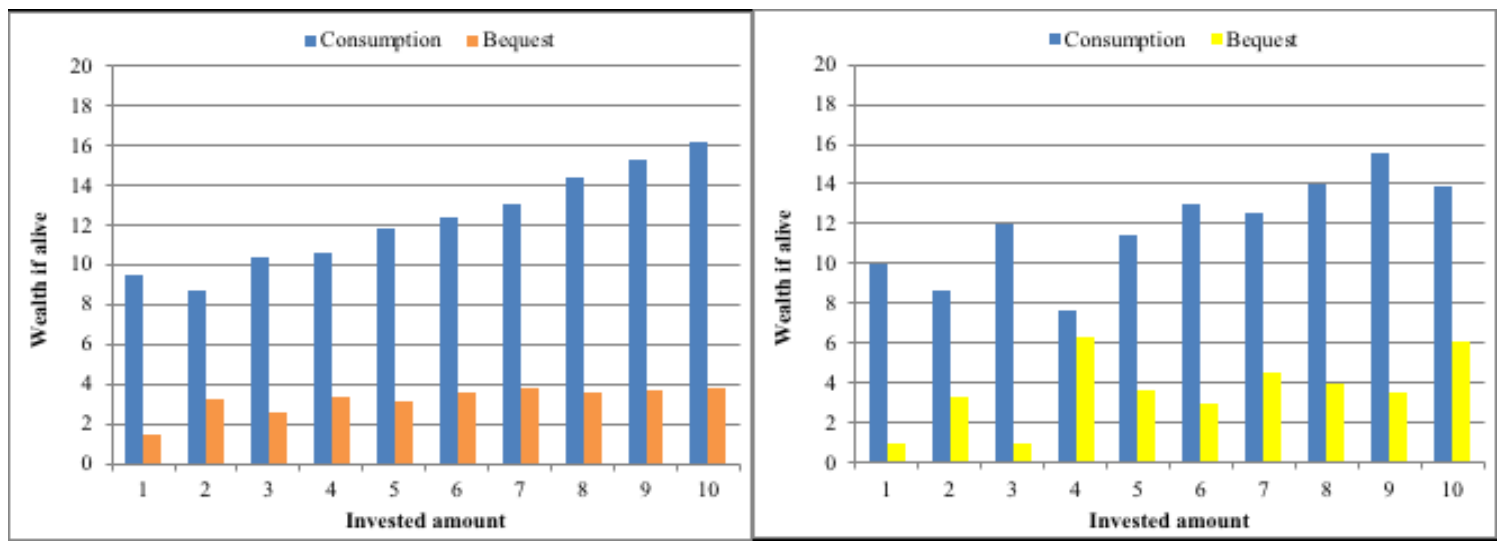

Figure 8. Subject's earnings and voluntary donations if active in period 2, by invested amount. Note: The left panel refers to all rational-KMM-coherent subjects (78 obs., red- and yellow-color charities of Figure 5). The right panel only refers to the subgroup of rational-KMM-coherent subjects who chose a national or local charity at the beginning of phase 2 (35 obs., only yellow-color charities of Figure 5).

The left panel of the Figure 8 shows a positive correlation between consumption if alive in period 2 and demand for annuities in period 1 (Spearman's rho $=0.59, p$-value $=$ 0.000 ). However, the correlation between the latter and voluntary bequest in period 2 is not significant (Spearman's rho $=0.14, p$-value $=0.216$ ). Both positive correlations are significant in the right panel of Figure 8 ( $r h o=0.47, p$-value $=0.004$ for consumption, $r h o$ $=0.31, p$-value $=0.071$ for bequest). This seems to suggest that for voluntary bequest to increase with the demand for annuities, a threshold level of warm glow should be overcome. This point deserves a more thorough discussion.

As anticipated in the previous section, here we rely on the distinction international vs. national (and local) charities, and elaborate the operational assumption that donating to a perceived closer charity (because of social identity, own participation, or friends/relatives involvement) generates more warm-glow altruism. 
As it is well known in the literature of charitable giving (see, e.g., Sargeant 2008), donors have a 'need to belong' - they need to feel that they are part of the charity. They should not just give to the charity, they should feel as a 'charity sponsor' or 'charity supporter'. However, it is not enough for them to feel how similar they are to the organization. They need to experience this for themselves. That is why charities try to involve their donors to take part in events and activities that let them experience similar beliefs and values being applied. Data of Table 2 in the previous section (see, e.g., the two dummies Charity Participation and Charity Relatives-Friends) show that in our sample this process applies more easily to local and national than to international charities.

The two OLS regressions in Table 3 capture this issue, raised by the analysis of the two panels of Figure 8. In Model I, the two explanatory variables are the amount invested in annuities in period 1, and a dummy (National Charity) indicating that the chosen charity at the beginning of phase B was a local or national one. The controls are the same as in Table 2, apart from charity-related variables, that are omitted due to positive correlation with the National Charity dummy. Model II, using the same control variables, proposes as regressor the interaction between the demand for annuities and the National Charity dummy. We can see that in Model I (in line with the left panel of Figure 8), the invested amount does not significantly boost the voluntary bequest, which instead significantly depends $(p$-value $=0.061)$ on the recipient being a local or national rather than an international charity.

In Model II, the interaction term is highly significant (since $p$-value $=0.017$ ), thus suggesting that the higher returns generated by a higher investment in annuities are used to also increase the next generation's wealth only if this generation is perceived as 'enough close'. Furthermore, the perception of one's own level of altruism toward a third person (Altruism Own in Table 2) significantly contributes to increase the voluntary bequest, thereby confirming a higher perceived warm glow when the donation recipient is a national rather than an international charity.

\begin{tabular}{lccccc}
\hline \hline Dep. var.: Voluntary Bequest & \multicolumn{2}{c}{ Model I } & \multicolumn{2}{c}{ Model II } \\
\hline \hline Invested Amount & 0.11 & $(0.13)$ & \multicolumn{2}{c}{-} \\
National Charity & $1.29^{*}$ & $(0.68)$ & \multicolumn{2}{c}{-} \\
\hline Invested Amount * National Charity & \multicolumn{3}{c}{-} & $0.15^{* *}(0.06)$ \\
\hline Altruism Own & 0.26 & $(0.16)$ & $0.26^{*}(0.16)$ \\
Female & -0.61 & $(0.65)$ & -0.73 & $(0.64)$ \\
Age & 0.12 & $(0.52)$ & 0.08 & $(0.51)$ \\
Economics & 0.22 & $(0.67)$ & 0.37 & $(0.65)$ \\
Treatment & -0.15 & $(0.68)$ & -0.29 & $(0.64)$ \\
\hline Constant & -0.56 & $(2.08)$ & 0.90 & $(1.78)$ \\
Adj. R-squared & \multicolumn{2}{c}{0.049} & \multicolumn{2}{c}{0.075} \\
No. of observations & \multicolumn{2}{c}{78} & \multicolumn{2}{c}{78} \\
\hline \hline
\end{tabular}

Table 3. OLS regressions explaining voluntary donation of rational-KMM-coherent subjects. Note: Standard errors in parentheses, ${ }^{*} p<0.1,{ }^{* *} p<0.05,{ }^{* * *} p<0.01$.

To summarize, we can state that hypothesis $\mathbf{3}$ is always verified for consumption: 
we find that the latter is significantly increasing in the demand for annuities both when considering all the rational-KMM-coherent subjects and when disentangling them by type of charities receiving the amount not consumed. Hypothesis $\mathbf{3}$ is verified for voluntary bequest only for sufficiently high levels of warm glow giving. In our experiment, this seems to occur for bequests toward local or national charities, but not for those directed to internationally well-known but less 'participated' charities.

\section{Conclusion}

Our study introduces a novel experimental design able to detect individuals' smooth ambiguity attitudes and relate them to life self-insurance decision problems. The experimental results support the intuition that ambiguity aversion may be a relevant motivation for the empirically observed under-annuitization puzzle when facing investment decisions where the (unknown) probability of being alive tomorrow is involved.

In fact, provided that annuities return is sufficiently larger than bonds return, and notably when - as in our experiment - it is fair, the optimal share of annuities in the portfolio should be positive. However, if the investor had a preference for known rather than unknown survival probabilities, he/she would find this financial instrument not so attractive. Thus, for a given level of uncertainty, an ambiguity-averse individual would invest less in annuities than an ambiguity-neutral one. This would ultimately reduce, upon survival, both his/her consumption and his/her bequest to the next generation, given that both should be increasing in the investment in annuities. Our experimental results confirm both these intuitions, by measuring ambiguity aversion within a KMM framework and employing donations toward a pre-selected charity as experimental proxies of warm-glow giving toward a related "next generation".

There is a growing experimental literature on the behavioral determinants of the demand for insurance (see, e.g., Corcos et al. 2017, and references therein), and on the impact of ambiguity aversion on insurance decisions (see, e.g., Di Mauro \& Maffioletti 1996, and Cabantous 2007). However, still few experimental studies have focused on annuities as an insurance instrument.

Among relevant exceptions, the potential impact of recent stock returns on annuitization decisions was tested in an experimental setting by Agnew et al. (2015), confirming the impact of recent market performance and attributing it to excessive extrapolation. Earlier experiments (Agnew et al. 2008) have focused on the effects of priming and framing on the demand for annuities. Experiments were also used to investigate the impact of changes in the structure of annuity products with predetermined default choices (Gazzale et al. 2012) and how the decision to retire could be affected by the offer of annuities in the market (Fatas et al. 2007).

More recently, Hurwitz et al. (2018) has investigated the introduction and repeal of mandatory minimum annuity laws in a laboratory experiment, and found that the demand for annuities was sensitive to the mandatory-minimum mechanism and consistent with anchoring to the signal reflected in the requirement.

However, to the best of our knowledge, ours is the first experimental test of the underannuitization puzzle employing at the same time individual (ambiguity attitude) and social 
(warm-glow giving) preferences. In this regard, the main finding of our study is that the under-annuitization puzzle is much more related to ambiguous survival probabilities than to a bequest motive.

The strong negative impact of ambiguity aversion on the demand for annuities detected in our experiment should convince private firms and public authorities to reshape current financial instruments of self-insurance for decision makers uncertain about the probability of being alive tomorrow. Indeed, ambiguity-averse investors might prefer financial products that combine an annuity and a life insurance, thereby hedging across different ambiguous states of the world. This would challenge the standard distinction between "death cover" and "survival cover" insurances in financial markets. We leave to future research the experimental test of the effectiveness of these mixed instruments of self-protection against ambiguous survival probabilities.

\section{References}

[1] d'Albis, H. and E. Thibault (2012), Optimal Annuitization, Uncertain Survival Probabilities and Maxmin Preferences, Economics Letters, 115, 295-299.

[2] d'Albis, H. and E. Thibault (2018), Ambiguous Life Expectancy and the Demand for Annuities, Theory and Decision, forthcoming.

[3] Agnew, J. R., Anderson, L. R., Gerlach, J. R. and L. R. Szykman (2008), Who Chooses Annuities? An Experimental Investigation of the Role of Gender, Framing, and Defaults, American Economic Review, 98, 418-422.

[4] Agnew, J. R., Anderson, L. R. and L. R. Szykman, (2015). An Experimental Study of the Effect of Market Performance on Annuitization and Equity Allocations, Journal of Behavioral Finance, 16, 120-129.

[5] Andreoni, J. (1989), Giving with Impure Altruism: Applications to Charity and Ricardian Equivalence, Journal of Political Economy, 97, 1447-1458.

[6] Attanasi, G., Gollier, C., Montesano, A. and N. Pace (2014), Eliciting Ambiguity Aversion in Unknown and in Compound Lotteries: A Smooth Ambiguity Model Experimental Study, Theory and Decision, 77, 485-530.

[7] Attanasi, G., Georgantzís, N., Rotondi, V. and D. Vigani (2018), Eliciting Risk Aversion Parameters from Different Incentivized Tasks: Correlation among Tasks and with Self-reported Risk Attitude, Theory and Decision, 84, 341-372.

[8] Bade, S. (2015), Randomization Devices and the Elicitation of Ambiguity-averse Preferences, Journal of Economic Theory, 159, 221-235.

[9] Bell, F. C. and M. L. Miller (2005), Life Tables for the United States Social Security Area, 1900-2100, Actuarial Study No. 120. SSA Pub. No. 11-11536. Social Security Administration, Office of the Chief Actuary. 
[10] Benartzi, S., Previtero, A. and R. H. Thaler (2011), Annuitization Puzzles, Journal of Economic Perspectives, 25, 143-164.

[11] Brown, A. L., Meer, J. and J. F. Williams (2013), Why Do People Volunteer? An Experimental Analysis of Preferences for Time Donations, NBER Working Paper No. 19066.

[12] Brown, J. R., Kling, J. R., Mullainathan, S. and M. V. Wrobel (2008), Why Don't People Insure Late-Life Consumption? A Framing Explanation of the UnderAnnuitization Puzzle, American Economic Review, 98, 304-309.

[13] Brown, J. R., Kling, J. R., Mullainathan, S. and M. V. Wrobel (2013), Framing Lifetime Income, Journal of Retirement, 1, 27-37.

[14] Cabantous, L. (2007), Ambiguity Aversion in the Field of Insurance: Insurers' Attitude to Imprecise and Conflicting Probability Estimates, Theory and Decision, 62, 219-240.

[15] Chakravarty, S. and J. Roy (2009), Recursive Expected Utility and the Separation of Attitudes towards Risk and Ambiguity: An Experimental Study, Theory and Decision, 66, 199-228.

[16] Conte, A. and J. D. Hey (2013), Assessing Multiple Prior Models of Behavior under Ambiguity, Journal of Risk and Uncertainty, 46, 113-132.

[17] Converse, B. A., Risen, J. L. and T. J. Carter (2012), Investing in Karma: When Wanting Promotes Helping, Psychological Science, 23, 923-930.

[18] Corcos, A., Pannequin, F. and C. Montmarquette (2017), Leaving the Market or Reducing the Coverage? A Model-based Experimental Analysis of the Demand for Insurance, Experimental Economics, 20, 836-859.

[19] Cox, J., Sadiraj, V. and U. Schmidt (2015), Paradoxes and Mechanisms for Choice under Risk, Experimental Economics, 18, 215-250.

[20] Crumpler, H. and P. J. Grossman (2008), An Experimental Test of Warm Glow Giving, Journal of Public Economics, 92, 1011-1021.

[21] Cutler, D. M. and E. Meara (2004), Changes in the Age Distribution of Mortality over the Twentieth Century, In: D. A. Wise (Ed.), Perspectives on the Economics of Aging, Chicago: University of Chicago Press, pp. 333-366.

[22] Davidoff, T., Brown, J. R. and P. A. Diamond (2005), Annuities and Individual Welfare, American Economic Review, 95, 1573-1590.

[23] Di Mauro, C. and A. Maffioletti (1996), An Experimental Investigation of the Impact of Ambiguity on the Valuation of Self-Insurance and Self-Protection, Journal of Risk and Uncertainty, 13, 53-71. 
[24] Edwards, R. D. and S. Tuljapurkar (2005), Inequality in Life Spans and a New Perspective on Mortality Convergence across Industrialized Countries, Population and Development Review, 31, 645-674.

[25] Fatas, E., Lacomba, J. A. and F. Lagos (2007), An Experimental Test on Retirement Decisions, Economic Inquiry, 45, 602-614.

[26] Gazzale, R., Mackenzie, S. and L. Walker (2012), Do Default and Longevity Annuities Improve Annuity Take-up Rates? Results from an Experiment, AARP Public Policy Institute Working Paper 2012-11.

[27] Gilboa, I. and D. Schmeidler (1989), Maxmin Expected Utility with Non-unique Prior, Journal of Mathematical Economics, 18, 141-153.

[28] Gollier, C. (2014), Optimal Insurance Design of Ambiguous Risks, Economic Theory, $57,555-576$.

[29] Greiner, B. (2015), Subject Pool Recruitment Procedures: Organizing Experiments with ORSEE, Journal of the Economic Science Association, 1, 114-125.

[30] Halevy, Y. (2007), Ellsberg Revisited: An Experimental Study, Econometrica, 75, 503-536.

[31] Hu, W.-Y. and J. S. Scott (2007), Behavioral Obstacles in the Annuity Market, Financial Analysts Journal, 63, 71-82.

[32] Hurwitz, A., Sade, O. and E. Winter (2018), Anchoring Bias in Annuity Choices: An Experimental Investigation, SSRN Working Papers 3117804.

[33] Kadane, J. B. (1992), Healthy Skepticism as an Expected-utility Explanation of the Phenomena of Allais and Ellsberg, Theory and Decision, 32, 57-64.

[34] Kellner, C., Reinstein, D. and G. Riener (2015), Stochastic Income and Conditional Generosity, Dusseldorf Institute for Competition Economics, Discussion Paper no. 197.

[35] Klibanoff, Marinacci, M. and S. Mukerji (2005), A Smooth Model of Decision Making under Ambiguity, Econometrica, 73, 1849-1892.

[36] Koch, P., Korwin-Szymanowska, C. and I. Ring (2015), Are You Ready for the Newlook UK Retirement Market?, McKinsey Quarterly, 15 October 2015.

[37] Inkmann, J., Lopes, P. and A. Michaelides (2011), How Deep Is the Annuity Market Participation Puzzle?, Review of Financial Studies, 24, 279-319.

[38] James, E., and X. Song (2001), Annuities Markets around the World: Money's Worth and Risk Intermediation, CeRP Working Paper 16/01.

[39] Johnson, R. W., Burman, L. E. and D. I. Kobes (2004), Annuitized Wealth at Older Ages: Evidence from the Health and Retirement Study, Washington D.C.: The Urban Institute. 
[40] Lockwood, L. M. (2012), Bequest Motives and the Annuity Puzzle, Review of Economic Dynamics, 15, 226-243.

[41] Oeppen, J. and J. W. Vaupel (2002), Broken Limits to Life Expectancy, Science, 296, 1029-1031.

[42] Post, T. and K. Hanewald (2013), Longevity Risk, Subjective Survival Expectations, and Individual Saving Behavior, Journal of Economic Behavior and Organization, 86, 200-220.

[43] Previtero, A. (2014), Stock Market Returns and Annuitization, Journal of Financial Economics, 113, 202-214.

[44] Reichling, F. and K. Smettters (2015), Optimal Annuitization with Stochastic Mortality and Correlated Medical Costs, American Economic Review, 105, 3273-3320.

[45] Riddel, M. and W. D. Shaw (2006), A theoretically-consistent Empirical Model of Non-expected Utility: An Application to Nuclear-waste Transport, Journal of Risk and Uncertainty, 32, 131-150.

[46] Sargeant, A. (2008), Donor retention: What do we know and what can we do about it. A Report for the Association of Fundraising Professionals, Washington DC.

[47] Schneeweiss, H. (1973), The Ellsberg Paradox from the Point of View of Game Theory, Inference and Decision, 1, 65-78.

[48] Viscusi, W. K. and J. E. Aldy (2003), The Value of a Statistical Life: A Critical Review of Market Estimates throughout the World, Journal of Risk and Uncertainty, $27,5-76$.

[49] Viscusi, W. K., Magat, W. A. and J. Huber (1991), Communication of Ambiguous Risk Information, Theory and Decision, 31, 159-173.

[50] Yaari, M. E. (1965), Uncertain Lifetime, Life Insurance, and the Theory of the Consumer, Review of Economic Studies, 32, 137-160.

[51] Yogo, M. (2016), Portfolio Choice in Retirement: Health Risk and the Demand for Annuities, Housing, and Risky Assets, Journal of Monetary Economics, 80, 17-34. 